\title{
Análise de elementos visuais em jogos digitais: a função da navegação, instrução e comunicação em dispositivos portáteis
}

\author{
The analysis of visual elements in digital games: the role of \\ navigation, instruction and communication devices portable
}

\author{
Bruno S. S. Farias, Mário Meireles Teixeira
}

Análise de jogos, dispositivos portáteis, funções dos elementos visuais

\begin{abstract}
Apresenta-se uma ferramenta de análise de elementos gráficos e estratégias de estruturação da informação nos jogos digitais em dispositivos portáteis. O objetivo desta ferramenta é verificar a ocorrência desses elementos quando empregadas nas funções interativas. Para tal, recorreu-se a pesquisa bibliográfica para determinar os tipos de elementos gráficos e as estratégias para estruturação da informação e realizou-se um teste piloto com sete jogos mediante pesquisa descritiva com abordagem qualitativa através do método indutivo de observação sistemática com registros fotográficos para mensurar os tipos de elementos gráficos mais utilizados nas funções interativas. Conclusões iniciais apontam possíveis vantagens para estratégias de na-vegação que valorizam deslocamento virtual e instruções contextualizadas, entre outras.
\end{abstract}

It presents an analysis tool of graphic elements and strategies for structuring information in digital games on handheld devices. The purpose of this tool is to check the occurrence of these elements when used in interactive functions. For such, was employed bibliographic research to determine the types of graphic elements and strate-gies for structuring information and a pilot test carried out with seven games through descriptive research with qualitative approach through the inductive method of systematic observation with photographic records to meas-ure types of graphic elements used in more interactive functions. Initial findings suggest potential benefits for navigation strategies that value virtual displacement and contextualized instruction, among others..

\section{Introdução}

A popularização de artefatos digitais, em especial o móvel e portátil, fez surgir novos campos do design até então pouco explorados. Esses dispositivos apresentam formas de interação particulares através de gestos e comunicam as informações aos usuários de forma 
diferenciada, utilizando mecanismos até então não explorados em computadores. Os jogos digitais se beneficiaram dessas novas formas de apresentação e interação da informação.

O presente estudo tem a finalidade de fomentar o corpo crítico sobre esse campo envolvendo temas do design da informação e design de interação em dispositivos portáteis. O objetivo da pesquisa é desenvolver uma ferramenta de análise que possa observar a ocorrência e assinalar quais elementos visuais são mais empregados em determinadas funções tais como de navegação, de instrução e comunicação interativa. Pretende-se, ainda, compreender quais características dos vários tipos de registros visuais são mais adequadas e em que situações são mais eficientes.

Utiliza-se pesquisa descritiva com abordagem qualitativa para analisar não o aspecto estético, mas sim o processo informacional dos elementos visuais. Emprega-se o método indutivo com observação sistemática dos componentes visuais.

Este estudo é parte do trabalho de dissertação desenvolvido no Mestrado em Design da Universidade Federal do Maranhão e encontra-se no estágio de validação da ferramenta, apresentando-se aqui o teste piloto com análise de sete jogos.

O presente artigo está organizado da seguinte forma: pesquisa bibliográfica para classificação dos elementos visuais, definições sobre dispositivos digitais e jogos portáteis, definição das funções e das estratégias de estruturação da informação; pesquisa descritiva com a configuração da tabela mediante os elementos, funções e estratégias definidas na pesquisa bibliográfica, apresentação da ferramenta e o teste piloto com análise de sete jogos digitais.

\section{Linguagem visual}

Os elementos visuais podem ser entendidos como componentes dos signos que são apresentados pelos jogos a fim de gerar uma mediação entre o jogo e o jogador. Tal entendimento permite que os elementos visuais sejam classificados de várias formas.

Twyman (1982, apud PETTERSSON, 2002, p. 65) desenvolveu um esquema no qual a linguagem é o canal de comunicação. Segundo o autor a linguagem gráfica é aquela produzida por marcas manuais ou mecânicas com o objetivo de comunicar uma mensagem. De acordo com esse esquema, há canais auditivos e visuais. O canal visual divide-se em gráfico e não gráfico (nongraphic). O gráfico por sua vez divide-se em verbal, pictórico e esquemático (schematic), como demonstra o esquema a seguir (Esquema 1). 


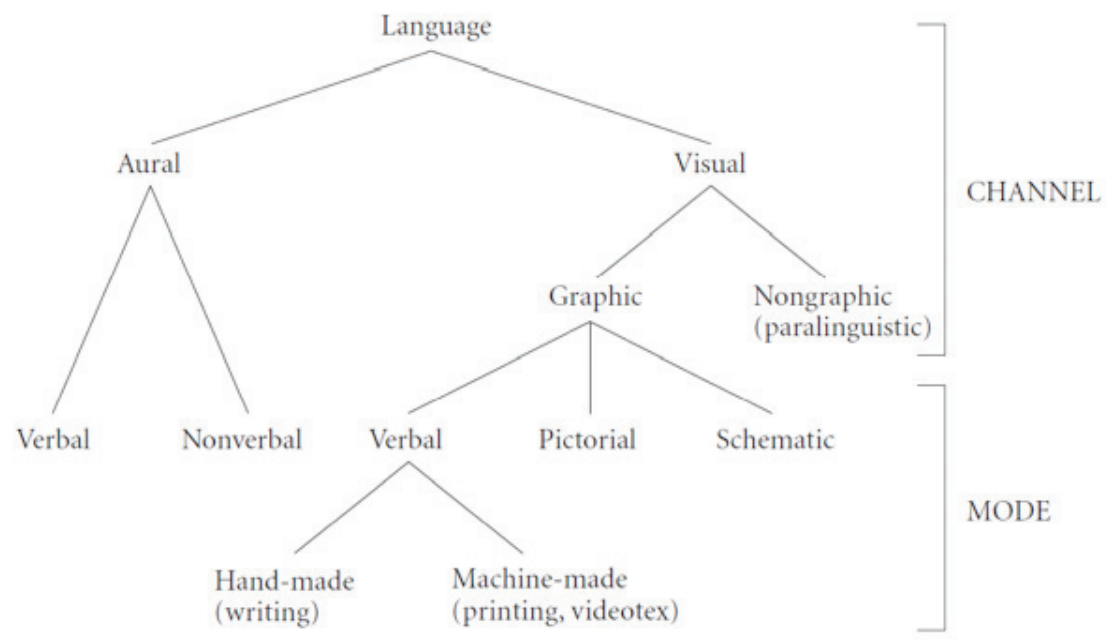

Esquema 1 - Elementos gráfico. Fonte: Pettersson (2002, p. 65)

O presente trabalho se utiliza dos elementos gráficos de Twyman (1982, apud PETTERSSON, 2002, p. 65) que têm como subdivisão a:

- Representação pictórica - que se refere às fotografias e ilustrações. A fotografia é uma representação mais realista, a ilustração é uma representação mais abstrata e simbólica;

- Representação esquemática - que se refere às imagens relacionadas com gráficos, tabelas e esquemas;

- Representação verbal - que se refere aos textos escritos.

Ao utilizar essa divisão, têm-se como objetivos: primeiro, um recorte para a pesquisa, pois se estuda apenas os elementos visuais; e segundo, uma forma de classificação para estruturar e analisar os elementos visuais. Vários autores comentam as propriedades destes elementos, como Arthur e Passini (2002), Souza (2012), Niemeyer (2010) e Padovani e Velozo (2007) que citam a:

- Eficiência na velocidade de percepção e interpretação da linguagem gráfica pictórica em detrimento da linguagem gráfica verbal.

- Eficiência na memorização, principalmente entre usuários experientes;

- Combinação dos modos verbais e pictóricos que favorecem a compreensão e eficácia para usuários inexperientes. A redundância está atrelada à previsibilidade, à repetição e ajuda a fixar a mensagem.

- Redução de esforço cognitivo, como a aprendizagem e a memória, quando a linguagem gráfica pictórica é empregada direcionando à atenção.

Em um processo semelhante à Twyman, Santaella (2005) elabora uma classificação baseada nos estudo de Pierce. A autora desenvolve 
as matrizes da linguagem: sonora, visual, verbal e híbrida. $\mathrm{Na}$ classificação da linguagem visual, Santaella (2005, p. 210) define:

- Forma figurativa - é a forma referencial que aponta para objetos ou situações reconhecíveis para fora da representação, por isso tem vocação mimética.

- Forma não representativa - diz respeito à redução da declaração visual das qualidades visuais como: cor, contornos, formas, movimento, ritmos, texturas entre outros.

- Forma representativa - é a forma visual convencionada, embora se exijam relações indi-ciais. Podem cobrir qualquer sistema visual codificado, como escrita, fórmulas matemáticas e químicas, etc.

Tanto a classificação de Twyman (1982, apud PETTERSSON, 2002, p. 65) quanto de Santaella (2005, p. 210) são utilizados na ferramenta de análise para descrever e identificar quais elementos são mais empregados nos jogos digitais. As qualidades visuais, características e classificações permitem conhecer o comportamento dos elementos gráficos empregados nos jogos digitais. Embora hajam inúmeros dispositivos digitais com propriedades e funções distintas, tais elementos permitem avaliar as informações pertinentes às funções dos artefatos.

\section{Definições sobre o contexto digital}

Há várias discussões sobre as diferenças entre os dispositivos móveis e portáteis. Souza (2012, p. 41) e Cybis et al (2010, p. 257) embora adotem taxonomias diferentes utilizam características semelhantes para definir dispositivos portáteis. Eles focam na portabilidade externa e interna e no manuseio com as mãos sem a necessidade de um suporte como uma mesa, por exemplo. A portabilidade externa se refere à possiblidade de movimentar o dispositivo fisicamente com facilidade. A portabilidade interna remete à capacidade de armazenamento e autonomia de energia do dispositivo. Deste modo, quando se utiliza o termo "dispositivo portátil" refere-se aos artefatos com essas características os quais pos-suem em geral uma tela sensível ao toque e são comandados por gestos. Dependendo da tarefa utilizam-se gestos específicos como toque simples, toques múltiplos, deslizar, entre outros.

Os jogos digitais em dispositivos portáteis se apropriam dessas qualidades para promover uma inte-ração mais significativa. $\mathrm{O}$ processo de interação nos jogos digitais é responsável por intermediar as ações, conectar os componentes e agir ou reagir, criando um relacionamento entre o jogo e o jogador.

O entendimento dessa relação advém primeiramente pelo próprio entendimento da expressão. O termo "jogos digitais" pode 
ser compreendido como uma abordagem envolvendo a tecnologia e elementos gráficos empregados. Salen e Zimmerman, (2009), Marcelo e Pescuite (2009) e Xavier (2010) adotam a expressão “jogos digitais" para representar não apenas processos eletrônicos ou uma sequência de atividades que são apresentadas em uma tela, mas uma estrutura lúdica baseada na linguagem visual manifestada que convida à interação. Tal definição permite afirmar que as linguagens gráficas permeiam todo o sistema do jogo, integrando-se com os componentes interativos.

O processo de assimilação da linguagem gráfica pelos jogos digitais ocorreu atraves de uma perspectiva tecnológica. Ao consultar Luz (2010), Aguiar (2010), Salen e Zimmerman, (2009) percebe-se que o desenvolvimento tecnológico contribuiu para o desenvolvimento gráfico, migrando de uma interface abstrata e simbólica para uma interface icônica realista. A assimilação das linguagens visuais ocorreu por empréstimos linguísticos dos quadrinhos, desenhos animados e cinema. A evolução tecnológica fez multiplicar o emprego de diversas linguagens como textos, imagens, sons, animações e outras, proporcionando a fragmentação visual.

Campos e Silva (2008) afirmam que esse processo de decompor para recompor se tornou a base do núcleo da informação beneficiando diversos tipos de funções interativas e promovendo várias estratégias de apresentação da informação.

\section{Estruturação da informação}

Os dispositivos digitais podem ser compreendidos como um sistema interativo nos quais possuem várias funcionalidades como processar, coletar, analisar, organizar, conectar e descrever a informação visando aumentar as possibilidades de encontrar uma resposta satisfatória às questões dos usuários, permitindo a realização das tarefas.

As tarefas dizem respeito às práticas humanas, considerando o contexto informacional do sis-tema. Não é o intuito deste artigo listar todas as tarefas dos dispositivos digitais, apenas as mais relevantes dos jogos digitais. Nesse sentido, considerou-se os estudos de Xavier (2010) e Cybis (2010) para as interfaces digitais e foram relacionadas três funções básicas que os elementos gráficos podem admitir nos jogos digitais:

- Navegação - é deslocamento no ambiente virtual que antecede a principal atividade do jogo. Esse deslocamento é motivado por interesses como definir uma tática, equipar o avatar, selecionar um equipamento, escolher uma fase, etc.

- Instrução - é atividade de treinar o jogador sobre os elementos do sistema, no qual permite que ele aprenda a controlar os componentes presentes. 
- Comunicação interativa - são os dispositivos de entrada e saída, os quais podem ocor-rer mediante elementos gráficos e/ ou gestuais.

Cada função relaciona-se com o nível de envolvimento que o usuário tem com o jogo. Cada função apresenta estratégias especificas no que se refere ao emprego dos elementos gráficos e na apresentação da informação.

\subsection{Navegação}

A primeira função dos elementos visuais é a navegação, que orienta o jogador a se deslocar e a configurar os componentes desejados. $\mathrm{O}$ emprego dos registros visuais relaciona-se as sinalizações do ambiente informando a posição relativa do usuário, onde ele deve ir, onde está o objetivo desejado, advertindo-o sobre ações ou situações que precisam de atenção.

Arthur e Passini (2002) apresentam o conceito de navegação baseado na capacidade cognitiva dos usuários e no conceito de mapa mental, que é a representação cognitiva do espaço físico, e apontam para dois tipos de mapas cognitivos, são eles:

- Memorização da rota - memoriza a distância, a mudança de direção e o ângulo da mudança.

- Relação topográfica - considera as relações entre os elementos e demais pontos de referência.

As estratégias adotadas pela navegação foram listadas por Neil (2012). Ela cita as avaliações do mercado para verificar as principais reclamações de usuários com relação aos dispositivos móveis. Duas dessas reclamações dizem respeito ao design: navegação ruim e interface confusa. Na tentativa de amenizar os problemas com interfaces, Neil (2012, p. 18) apresenta algumas estratégias de auxílio à navegação são elas:

- Menu de lista - organizada verticalmente em estrutura linear, bom desempenho para títulos longos ou para os que requerem subtexto.

- Abas - organizadas horizontalmente em uma estrutura linear, permite acesso rápido a outras seções.

- Galeria - exibe itens em uma estrutura ortogonal de conteúdo individual para navegação, geralmente pictórico.

- Carrossel - padrão de navegação usado para navegar rapidamente por um conjunto discreto de páginas ou imagens usando o gesto. 
A figura 1 apresenta o modelo de Neil (2012) onde se verificam as referidas estratégias de apresentação da informação.

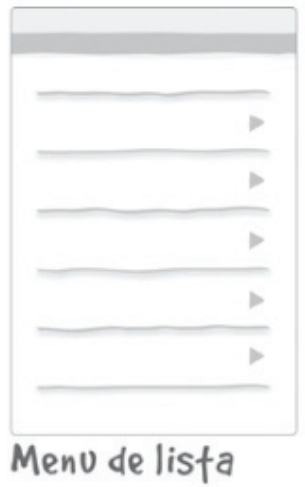

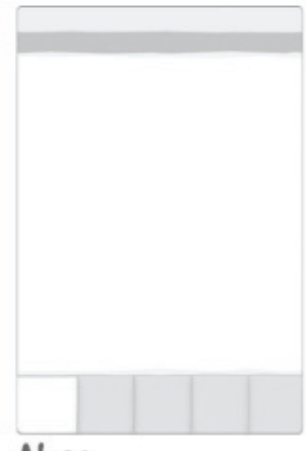

Abas

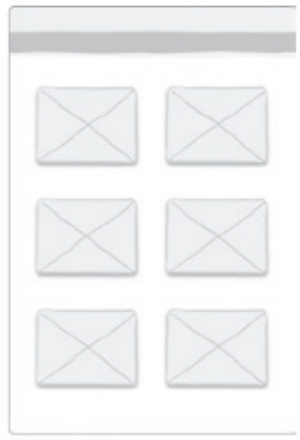

Galeria

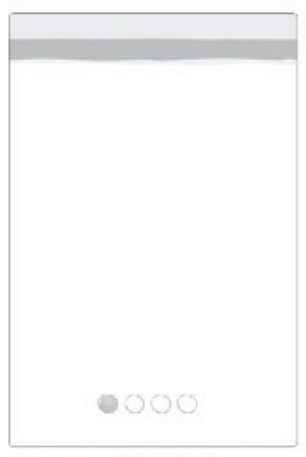

carrossel de páginas

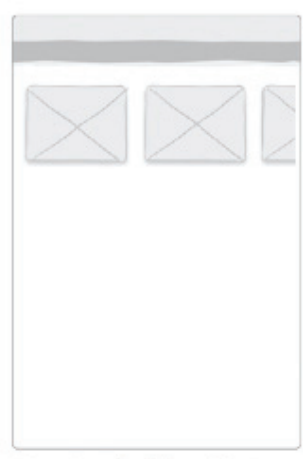

Carrossel de imagens

Figura 1 Sistema de Navegação (Fonte: Neil, 2012)

Neste trabalho, optou-se por agrupar as estratégias de navegação, citadas por Neil (2012) e nos conceitos apresentados por Arthur e Passini (2002). Deste modo, as estratégias ficaram organizadas da seguinte forma:

- Memorização por rota: quando os elementos indicam movimento para apresentar várias opções em páginas diferentes, assim as navegações por carrossel de páginas e carros-sel de imagens se encaixam nessa classificação.

- Relação topográfica: quando os elementos são todos apresentados na interface sem a necessidade de ter outras telas, assim a navegação por menu de lista, abas e galeria se encaixam nessa classificação.

Optou-se por fazer essa mescla para permitir uma análise mais precisa das estratégias empregadas pelos jogos e ter também uma base teórica consistente para discussão.

\subsection{Instruções visuais}

A instrução é a segunda função que os elementos visuais admitem e tem a finalidade de orientar o jogador na interação com os componentes da interface. Joly (1994, p. 47) afirma que frequentemente as imagens servem como suporte ao aprendizado. Com a recente popularização dos artefatos portáteis, surgiu um novo campo de atuação do design da informação, preocupado com instruções, utilização e manuseio de produtos digitais.

As instruções possuem uma finalidade prática, buscar a informação para realizar a tarefa. Desta forma, as instruções demandam 
competências linguísticas, cognitivas e motoras. O objetivo fim das instruções visuais é otimizar a construção de planos de ação.

Dentre as estratégias adotadas das instruções visuais encontra-se a representação dos proce-dimentos, ou passos das instruções, organizados em etapas que flexibilizam o tempo da ação. A temporização da ação é fator crucial no processo de aprendizagem. Se a instrução for muito rápida, com movimentos abruptos ou imprevisíveis, podem comprometer o processo de instrução (SPINILLO et al, 2010).

Nos jogos digitais é comum utilizar Sequências Pictóricas Animadas (SPA), que são movimentos dos elementos gráficos que simulam e aproximam a representação da ação. As SPA envolvem a manipulação do dispositivo e a interação entre a informação e a realização da tarefa, alternando assim a atenção do usuário entre o jogo e a instrução. Desta forma, dependendo das necessidades informacionais durante a execução da tarefa o usuário poderá pausar, retroceder, repetir a tarefa ou a instrução.

A facilidade de estilizar o tempo em dispositivos digitais permite que uma mesma ação possa ser apresentada em tempo real (ou tempo espontâneo), tempo acelerado ou mais lento. Nunes (1988) argumenta que podem existir duas noções de tempo:

- Tempo do conteúdo - também chamado de tempo efetivo. Seria a duração natural do evento relatado.

- Tempo do discurso - sujeito às características da forma através da qual é apresentado.

Além da apresentação, dos aspectos de planejamento e da estilização do tempo, outros componentes relacionados à instrução são o acesso e o momento de apresentação. É comum para muitos jogos permitir que o usuário possa acessar pelo menu a instrução a fim de eliminar dúvidas ou relembrar algum aspecto esquecido.

À medida que os usuários se deslocam e aprendem a utilizar os componentes do jogo é necessário informar as mudanças de estado do sistema interativo, essa é a atribuição da terceira função, comunicação interativa.

\subsection{Comunicação Interativa}

As interações possuem formas ativas de comunicação onde o jogador aciona os recursos dos jogos e obtém respostas distintas e imediatas (CYBIS et al, 2010, p. 257). Rogers et al (2013, p. 26) citam alguns princípios que são comuns em sistemas digitais, são eles:

- Visibilidade: quanto mais visíveis forem às funções mais os usuários saberão como proceder. Em contrapartida, quando as 
funções não estão visíveis, torna-se mais difícil de encontrá-las e de saber como usá-las.

- Feedback: está relacionado ao conceito de visibilidade, pois está associado ao retorno da informação a respeito da ação realizada, permitindo, ou não, o usuário continuar a ação. Há vários tipos de feedback em dispositivos portáteis: auditivo, verbal, visual ou combinações destes.

- Restrição: refere-se ao tipo de limitações que os usuários podem se deparar em um de-terminado momento, desta forma, termina por orientar o usuário a tomar a decisão correta, ou no caso dos jogos, elevar o nível de dificuldade. Há várias formas de realizar isso: desativar funções, fluxogramas mostrando as relações das funções com determinados objetos ou relação formal, mostrando que determinado objeto se encaixa em determinada área.

Ainda sobre visibilidade, há uma questão nela relacionada que não foi explicitada, o mapeamento que refere-se à forma com que as ações humanas são conectadas às ações do sistema, ou seja, o "controle". Primo e Cassol (1999) observam que os controles podem ocorrer de forma arbi-trária ou natural. A arbitrária ocorre quando o usuário digita linhas de comando para acionar as funções. A natural é mais comum nos jogos digitais no qual há algum tipo de painel de controle e o usuário precisa indicar qual botão deseja acionar.

Observando os jogos em dispositivos portáteis verificou-se que há uma terceira forma de controle, a gestual, que não ocorre por linhas de comando ou por elementos pictóricos, apenas pelos movimentos das mãos. Essa nova forma pode ter relevante impacto na construção das interfaces, no uso dos elementos visuais e na carga cognitiva, uma vez que ao se utilizar de gestos específi-cos sem ter uma área prédeterminada se oculta os elementos visuais.

A discussão sobre a complexidade dos sistemas digitais e o nível de automação possibilitou o surgimento de algumas visões sobre o assunto. Norman (2010, p. 43) compara o nível de automação de sistemas interativos com as emoções do cérebro humano. Primo e Cassol (1999) se fundamentam no nível de controle do usuário. A tabela 1 apresenta um resumo entre as duas classificações:

Tabela 1 Tabela-Resumo dos Níveis de automação de sistemas interativos

\begin{tabular}{ll}
\hline NORMAN & PRIMO E CASSOL \\
\hline $\begin{array}{l}\text { Visceral - é o processamento automático, no nível do } \\
\text { subconsciente, determinada pela experiência. }\end{array}$ & $\begin{array}{l}\text { Proativo - quando o usuário controla o conteúdo e a } \\
\text { estrutura da informação. }\end{array}$ \\
\hline $\begin{array}{l}\text { Comportamental - são as habilidades aprendidas, mas na sua } \\
\text { maior parte controladas pelo subcons-ciente, administra as } \\
\text { expectativas das ações. }\end{array}$ & $\begin{array}{l}\text { Coativo - quando o usuário controla a sequência, o ritmo } \\
\text { e o estilo. }\end{array}$ \\
\hline
\end{tabular}


Farias, B. S. S. \& Teixeira, M. M. | Análise de elementos visuais em jogos digitais: a função da navegação, instrução e comunicação em dispositivos portáteis

Tabela 1 Tabela-Resumo dos Níveis de automação de sistemas interativos

Reflexivo - é a parte consciente do cérebro, que analisa a estratégia e as ações futuras.
Reativo - quando o usuário tem pouco controle sobre a estrutura e do conteúdo.

A automação tem impacto na sobrecarga cognitiva que os sistemas interativos provocam. No entanto, a automação é a estratégia para reduzir esse esforço automatizando algumas funções. Analisar esses autores é discutir a estratégia mais empregada e mais eficiente que os jogos digitais utilizam. Primo e Cassol (1999) nas suas categorias expressam um relacionamento entre o usuário e o sistema interativo, no qual, em determinados momentos, um assume o controle da tarefa. Norman (2010) por sua vez se baseia no comportamento humano e no nível de aprendiza-gem na realização da tarefa. Optou-se pela classificação de Norman (2010) pela relação que ele faz com a aprendizagem, que pode fornecer um vínculo com as questões da instrução.

Diante de tudo que foi exposto, foram realizados testes pilotos para organizar, adequar e vali-dar essas teorias no contexto de jogos digitais em dispositivos portáteis. A tabela que foi desenvolvida e aplicada encontra-se no Apêndice A.

\section{Ferramenta de análise de elementos visuais em jogos digitais}

\subsection{Definição da técnica de análise}

A ferramenta de análise foi desenvolvida para observar a frequência das variáveis e apontar pos-síveis tendências de uso, bem como dialogar com teorias de jogos, de design de informação e design de interação. Para registro dos elementos foi realizado captura de tela, técnica conhecida como screenshot, baseada na captura visual do momento que as variáveis aparecem.

A seleção dos jogos foi baseada na amostra probabilística, no qual, cada elemento tem igual probabilidade de ser escolhido (OLIVEIRA, 2010, p. 89). No caso da presente pesquisa levou-se em conta os recursos disponíveis, utilizou-se um tablet, modelo ipad, da Apple, que centraliza o acesso aos jogos via Appstore. Para manter a imparcialidade na seleção foram escolhidos sete de quatro categorias, baseados na sua popularidade.

De acordo com Xavier (2007), apresenta-se a classificação por gênero: Ação e exploração, aventura, estratégia, RPG, casuais, esportivos e simuladores. Optou-se em analisar jogos de várias categorias em razão de verificar a possiblidade da ferramenta de jogos digitais ser genérica na análise. 
Farias, B. S. S. \& Teixeira, M. M. | Análise de elementos visuais em jogos digitais: a função da navegação, instrução e comunicação em dispositivos portáteis

\subsection{Análise de jogos digitais}

Foram selecionados sete jogos digitais, de acordo com as popularidades em suas respectivas ca-tegorias, todos disponíveis no Appstore. A análise completa encontra-se no Apêndice A, o que será apresentado são as conclusões iniciais (Tabela 2):

Tabela 2 Tabela das conclusões iniciais

\section{Navegação}

\section{a. estratégia de navegação}

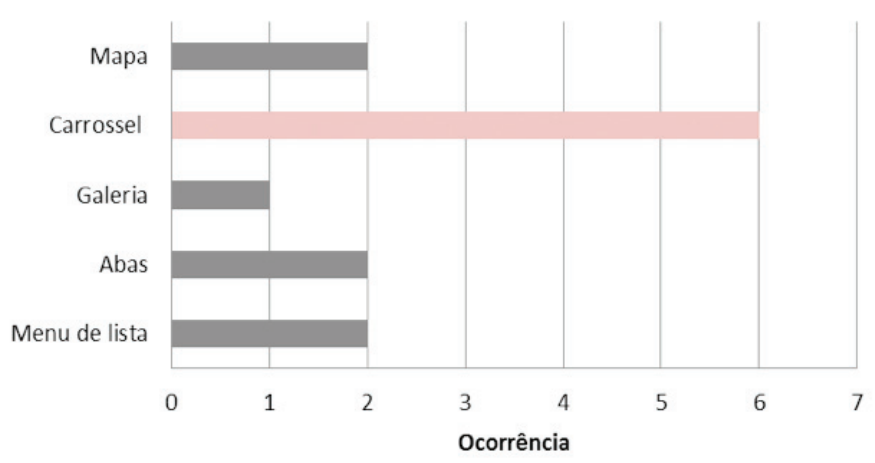

- O deslocamento virtual por carrossel de imagem teve destacada ocorrência podendo indicar que estruturas que evidenciam o deslocamento visual podem permitir uma melhor vi-sualização da posição dos elementos, uma vez que o usuário móvel divide a atenção com outros dispositivos, tarefas e ambientes.

\section{b. Ocorrência dos elementos de orientação por jogo}

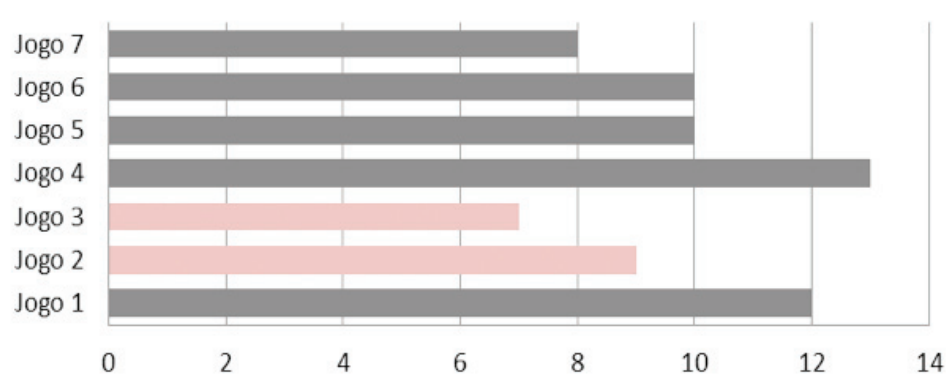

- Analisando o total de ocorrências que cada jogo tem (total vertical) percebe-se que os dois jogos (o 2 e 3 ) que possuem navegação por deslocamento virtual utilizando mapa são os que tem menores ocorrências de elementos por jogo (nove e sete ocorrências), in-dicando que esse tipo de navegação talvez seja a mais eficiente forma de se deslocar por jogos digitais em dispositivos portáteis uma vez que emprega menos elementos. 
Tabela 2 Tabela das conclusões iniciais

\section{Instrução}

\section{a. Momento da instrução}

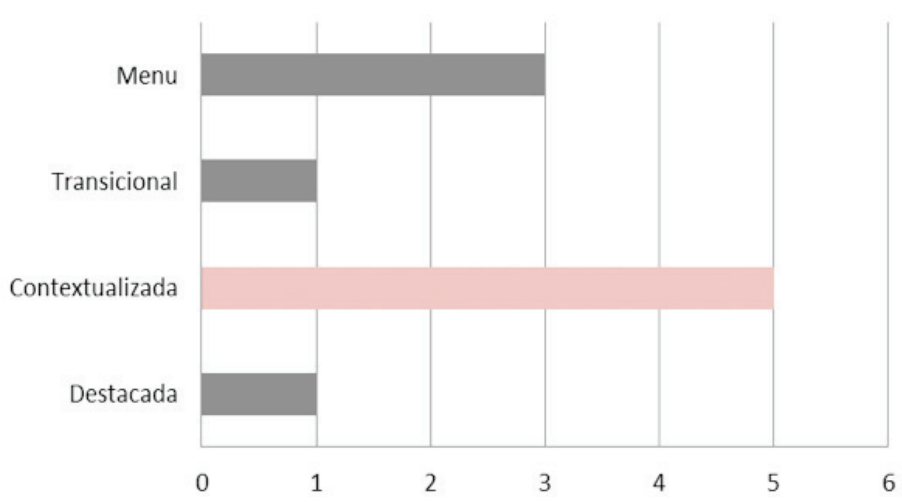

- A instrução contextualizada, que obteve quase que a totalidade das ocorrências, talvez seja a estratégia mais eficiente para ensinar ao usuário inexperiente devido a seu caráter de proximidade com o jogo em si.

- É fundamental reconhecer se o usuário é experiente ou não, daí a explicação que quase todos os jogos analisados possuem recursos para reconhecer o jogador.

\section{Comunicação Interativa}

\section{a. Ocorrência da comunicação interativa por jogo}

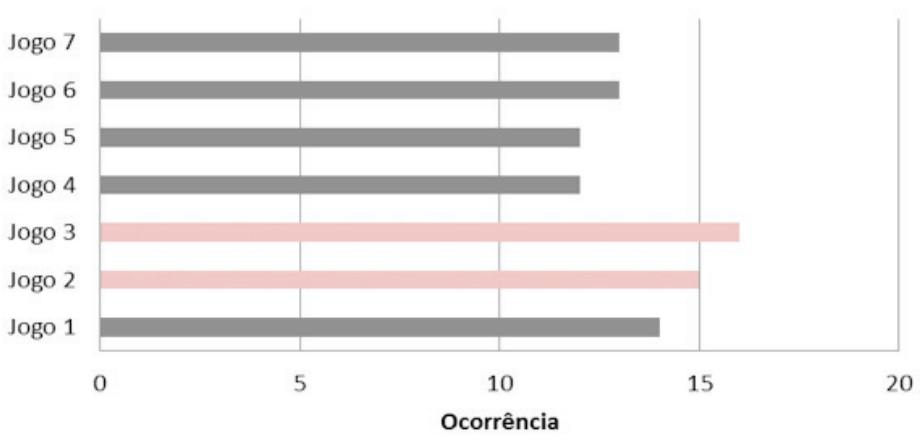

- Os jogos que empregaram o estilo de controle visual possuem a maior quantidade de elementos comunicativos. É possível que essa característica seja devido ao fato de os jo-gos que utilizam controle gestual não empregam elementos visuais nos controles, poden-do ter um forte impacto na carga cognitiva do usuário.

\section{Linguagem Visual}

\section{a. Linguagem}

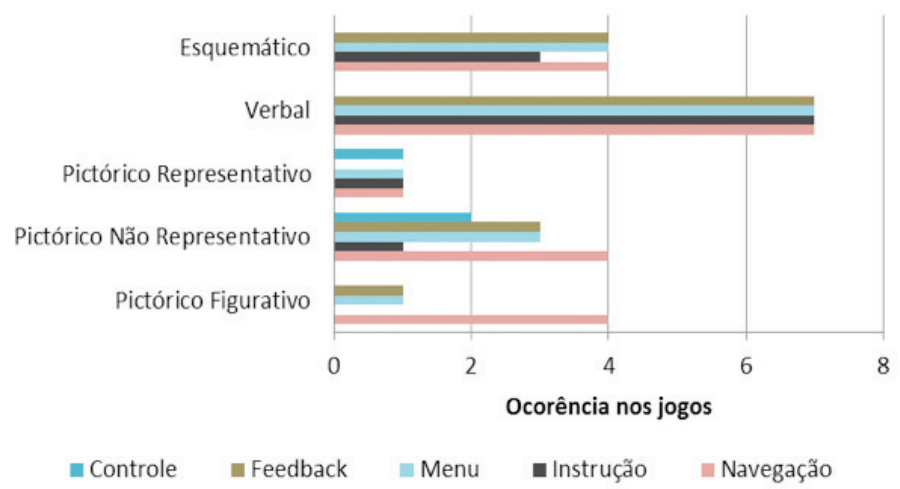

Infodesıgn | São Paulo | v. 10 | n. 3 [2013], p. 245 - 261 
Tabela 2 Tabela das conclusões iniciais

- A linguagem verbal é o principal tipo de linguagem empregada, visto que teve destaque na estratégia de navegação, estratégia de instrução, no menu e feedback. Muitas vezes ancorando o sentido da imagem, outras explicando sozinho. Esse fato pode ser explicado pelo caráter conciso desta linguagem. Enquanto elementos pictóricos são universais, a linguagem verbal é precisa.

- A linguagem pictórica não aparece com destaque como a linguagem verbal devido ao fato dela ter sido desmembrada, enquanto a verbal não. Com isso no acumulado da ocorrên-cia é diluída pelas categorias da linguagem pictórica. No entanto, interessante notar que formas que reduzem as qualidades de informações como a não representativa e a figura-tiva se destacaram, principalmente na navegação. Tal fato pode ser atribuído a redução da carga cognitiva que a forma representativa possa causar.

Evidente que uma análise com sete jogos em um universo de centenas de milhares é apenas um ponto de partida, fazendo-se necessário aumentar a amostra para chegar a resultados que possam ser generalizados. No entanto, os pontos levantados podem indicar certos caminhos de investigação que precisam ser confirmados. Alguns pontos, ainda, podem necessitar de outro tipo de pesquisa, como a experimental, controlando as variáveis, embora a pesquisa descritiva com observação sistemática foi capaz de demonstrar a aplicabilidade da ferramenta de análise de jogos desenvolvida.

\section{Conclusão}

O presente trabalho fez um estudo sobre as funções dos elementos visuais em jogos digitais em dispositivos portáteis. Foram determinadas três funções: navegação, instrução e comunicação interativa. Para analisá-las, foi desenvolvida uma ferramenta descritiva a fim de verificar a ocorrência dos registros visuais e que tipos de elementos são empregados.

O compromisso dessa pesquisa foi em estruturar a ferramenta de análise. Para tal foram definidos os campos de análise como a semiótica, design de informação e design de interação para levantar as variáveis de estudo, cominando com o teste piloto apresentado analisando sete jogos de quatro categorias. A escolha de trabalhar com gêneros diferentes objetivou verificar se a pre-sente ferramenta é genérica o suficiente.

O teste piloto foi considerado satisfatório comprovando a eficácia da ferramenta em analisar elementos visuais bem como levantar alguns questionamentos sobre a eficiência dos registros na navegação, instrução e comunicação.

Apesar de ter analisado uma amostra pequena do universo dos jogos digitais algumas obser-vações merecem uma investigação mais detalhada, como:

- A valorização do deslocamento virtual por carrossel, podendo indicar algumas vantagens dessa estratégia em detrimento das outras. 
- A navegação por mapas pode gerar uma carga cognitiva menor comparado a outras estra-tégias de navegação.

- A instrução que ocorre no contexto de jogo pode ser a mais eficiente forma de instrução.

- Controles gestuais podem se tornar uma tendência em jogos portáteis uma vez que em-pregam menos elementos visuais diminuindo assim o esforço cognitivo.

- A linguagem verbal tem destaque nos jogos digitais e os elementos pictóricos que se des-tacam são os que abstraem algumas qualidades visuais como cor, textura, volume.

Com isso, preliminarmente, pode-se induzir que nos jogos digitais em dispositivos portáteis os elementos visuais tendem a empregar qualidades gráficas a fim de reduzir o esforço cognitivo de usuários.

Pretende-se aumentar a amostra dos jogos analisados para verificar as hipóteses levantadas e em seguida realizar um estudo experimental avaliando a eficiência de cada elemento no contexto dos jogos digitais e confrontar os dados das diferentes pesquisas.

\section{Referências}

AGUIAR, M. P. (2010). Jogos eletrônicos educativos: instrumento de avaliação focado nas fases iniciais do processo de design. 2010, 300 f. Dissertação (Mestrado em Design). Universidade Federal do Paraná..

ARTHur, P.; PASSINI, ROMEDI. (2002). Wayfinding: People, Signs, and Architecture. Ontario: McGraw-Hill Ryerson Ltd.

CAMPOS, J. L. DE; SILVA, W. V. (2008). O design e a representabilidade dos signos dentro da word wide web. InfoDesign Revista Brasileira de Design de Informação. Curitiba, v. 1, n. 5, p 12-20, 2008.

CYBIS, w. (2010). Ergonomia e usabilidade: conceitos, métodos e aplicações. São Paulo: Novatec.

JOLY, M. (2007). Introdução à análise da imagem. Lisboa: Papirus.

LUZ, A. R. (2012). Vídeo game: historia, linguagem e expressão gráfica. São Paulo: Blucher.

MARCELO, A.; PESCUITE, J. (2009). Fundamentos de design para jogos: um guia para $o$ projeto de jogos modernos reais e virtuais. Rio de janeiro: Brasport. MARCONi, M. A.; LAKATOS, E. M. (2011). Metodologia cientifica. São Paulo: Altas. NEIL, T. (2012). Padrões de design para aplicativos móveis. São Paulo: Novatec. NIEMEYER, L. (2010). Elementos de semiótica aplicados ao design. Rio de Janeiro: $2 \mathrm{AB}$.

NORMAn, D. A. (2010). O design do futuro. Rio de Janeiro: Rocco. Nunes, B. (1988). O tempo da narrativa. São Paulo: Ática. oliveira, M. M. (2010). Como fazer pesquisa qualitativa. Petrópolis, RJ: Vozes. PAdovani, s.; VElozo, J. (2007). Melhorando a usabilidade de mapas de navegação em hipertextos através de técnicas de diferenciação. InfoDesign Revista Brasileira de Design de Informação. Curitiba, v. 2, n. 2, p 39-49. 
PETtersson, R. (2002). Information design: an introduction. Philadelphia: John Benjamins Pub-lishing Company.

PRIMO, A. F. T.; CASSOL, M. B. F. (1999). Explorando o conceito de interatividade: definições e taxonomias. Revista Informática na Educação: teoria e prática. Rio Grande do Sul: v. 2, n. 2, p. 65-80. outubro de 1999.

ROGERS, Y.; HELEN, S.; PREECE, J. (2013). Design de interação: além da interação humano-computador. 3a ed. Porto Alegre: Bookman.

SAlen, K.; Zimmerman, E. (2012). Regras do jogo: fundamentos do design de jogos: principais conceitos. Vol.1. São Paulo: Blucher.

SANTAELla, L. (2005). Matriz da linguagem e pensamento. 3a Ed. São

Paulo: Iluminuras.

SouZA, A. P. (2012). Animação Multimídia de Instrução (AMI) visualizada em Dispositivo de Interação Móvel (DIM): um estudo exploratório acerca da influência da flexibilidade de interação sobre a visualização da informação e a realização da tarefa. 2012, 193 f. Dissertação (Mestrado em Design). Universidade Federal do Paraná.

SPINILlO, C. G.; SOUZA, J. M. B.; MAIA, T. C.; STORCK, G. R.; OSE-LAME, A. (2010). Representação Gráfica de Instruções Visuais Animadas: um estudo analítico na perspectiva da ergonomia informacional. In: Congresso Internacional de Ergonomia e Usabilidade de Interfaces Humano-Computador, 10. 2010, Rio de Janeiro: Anais do 100 congresso internacional de ergonomia e usabilidade de interfaces humano-computador. Rio de Janeiro: ed. PUC-Rio.

XAVIER, G. (2007). Imagética Eletrolúdica: a visualidade dialógica no multiverso dos jogos eletrônicos. Rio de Janeiro, 2007. 195 f. Dissertação (Mestrado em Artes e Design) - Departamento de Ar-tes e Design, Pontifícia Universidade Católica do Rio de Janeiro.

XAVIER, G. (2010) Cultura visual nos jogos eletrônicos. Teresópolis: Nova Ideia.

\section{Sobre os autores}

Bruno S.S. Farias, <brunoserviliano@gmail.com> Mestrando em Design pela Universidade Federal do Maranhão, professor substituto da UFMA. Atua nos seguintes temas: linguagem visual, design de informação e jogos digitais.

\section{Mário Teixeira,}

<mario@deinf.ufma.br>

Doutor em Ciências da Computação e Matemática Computacional pela Universidade de São Paulo (2004), professor associado da UFMA e Coordenador do Mestrado em Ciência da Computação, além de Secretário Regional da SBC para o Maranhão. Atua principalmente nos seguintes temas: sistemas distribuídos, serviços web, TV digital interativa e redes peer-to-peer.

Artigo recebido em 02 dez. 2013, aprovado em 21 dez. 2013. 


\section{Apêndice A: Ferramenta de análise de elementos visuais de jogos digitais em dispositivos} portáteis

1. Badland, 2. The Dark Kngith Rise, 3. O Espetacular Homem Aranha, 4. Injustices, 5. Plant vs. Zumbi, 6. Sonic Dash, 7. Sonic Racing

Jogos Analisados

\begin{tabular}{|c|c|c|c|c|c|c|c|c|c|c|}
\hline \multicolumn{11}{|c|}{ A. Elementos de orientação } \\
\hline \multirow{10}{*}{$\begin{array}{l}\text { Estratégias de } \\
\text { Navegação }\end{array}$} & \multirow{5}{*}{ Elemento Gráfico } & Pictórico Figurativo & $x$ & & & $x$ & & $x$ & $x$ & 4 \\
\hline & & $\begin{array}{l}\text { Pictórico Não } \\
\text { RepresentWativo }\end{array}$ & $x$ & & $x$ & $x$ & $x$ & & & 4 \\
\hline & & Pictórico Representativo & & & & $x$ & & & & 1 \\
\hline & & Verbal & $x$ & $x$ & $x$ & $x$ & $x$ & $x$ & $x$ & 7 \\
\hline & & Esquemático & $x$ & & & $x$ & & $x$ & $x$ & 4 \\
\hline & \multirow{3}{*}{ Relação gráfica } & Lista & & $x$ & & $x$ & & & & 2 \\
\hline & & Abas & & & & $x$ & & $x$ & & 2 \\
\hline & & Galeria & & & & & $x$ & & & 1 \\
\hline & \multirow{2}{*}{ Deslocamento virtual } & Carrossel & $x$ & $x$ & & $x$ & $x$ & $x$ & $x$ & 6 \\
\hline & & Mapa & & $x$ & $x$ & & & & & 2 \\
\hline \multirow{14}{*}{$\begin{array}{l}\text { Estratégias de } \\
\text { Instrução }\end{array}$} & \multirow{5}{*}{ Elemento Gráfico } & Pictórico Figurativo & & & & & & & & 0 \\
\hline & & Pictórico Não Representativo & $x$ & & & & & & & 1 \\
\hline & & Pictórico Representativo & $x$ & & & & & & & 1 \\
\hline & & Verbal & $x$ & $x$ & $x$ & $x$ & $x$ & $x$ & $x$ & 7 \\
\hline & & Esquemático & $x$ & & & & $x$ & $x$ & & 3 \\
\hline & \multirow{4}{*}{$\begin{array}{l}\text { Momento da } \\
\text { Apresentação }\end{array}$} & Destacada & & & & & & & $x$ & 1 \\
\hline & & Contextualizada & & $x$ & $x$ & $x$ & $\mathrm{x}$ & $x$ & & 5 \\
\hline & & Transicional & & $x$ & & & & & & 1 \\
\hline & & Menu & $x$ & & & $x$ & $x$ & & & 3 \\
\hline & \multirow{2}{*}{ Estilização do tempo } & Tempo do conteúdo & & & $x$ & & $\mathrm{x}$ & $x$ & & 3 \\
\hline & & Tempo do discurso & $\mathrm{x}$ & $x$ & & $x$ & & $x$ & & 4 \\
\hline & \multirow{2}{*}{$\begin{array}{l}\text { Reconhecimento do } \\
\text { Usuário }\end{array}$} & Sim & & $x$ & $x$ & $\mathrm{x}$ & $x$ & $x$ & $x$ & 6 \\
\hline & & Não & $x$ & & & & & & & \\
\hline & & Total & 12 & 9 & 7 & 13 & 10 & 10 & 8 & 69 \\
\hline
\end{tabular}

B. Processo de Comunicação Interativa

logos Analisados

\begin{tabular}{|c|c|c|c|c|c|c|c|c|c|c|}
\hline & & & 1 & 2 & 3 & 4 & 5 & 6 & 7 & Total \\
\hline \multirow{9}{*}{ Menu } & \multirow{5}{*}{ Linguagem } & Pictórico Figurativo & & $x$ & & & & & & 1 \\
\hline & & Pictórico Não Representativo & $x$ & & $x$ & & & $x$ & & 3 \\
\hline & & Pictórico Representativo & $x$ & & & & & & & 1 \\
\hline & & Verbal & $x$ & $x$ & $x$ & $\mathrm{x}$ & $x$ & $x$ & $x$ & 7 \\
\hline & & Esquemático & $x$ & $x$ & $x$ & & $x$ & & & 4 \\
\hline & \multirow{2}{*}{ Apresentação } & Lista & & $x$ & $x$ & $x$ & & $x$ & $x$ & 5 \\
\hline & & Conceitual & $x$ & & $x$ & & $x$ & & & 3 \\
\hline & \multirow{2}{*}{ Relação com o jogo } & Opcao & $x$ & $x$ & $x$ & & & & & 3 \\
\hline & & Translúcido & & & & $x$ & $x$ & $x$ & $x$ & 4 \\
\hline
\end{tabular}


Farias, B. S. S. \& Teixeira, M. M. | Análise de elementos visuais em jogos digitais: a função da navegação, instrução e comunicação em dispositivos portáteis

\section{B. Processo de Comunicação Interativa}

(Conclusão)

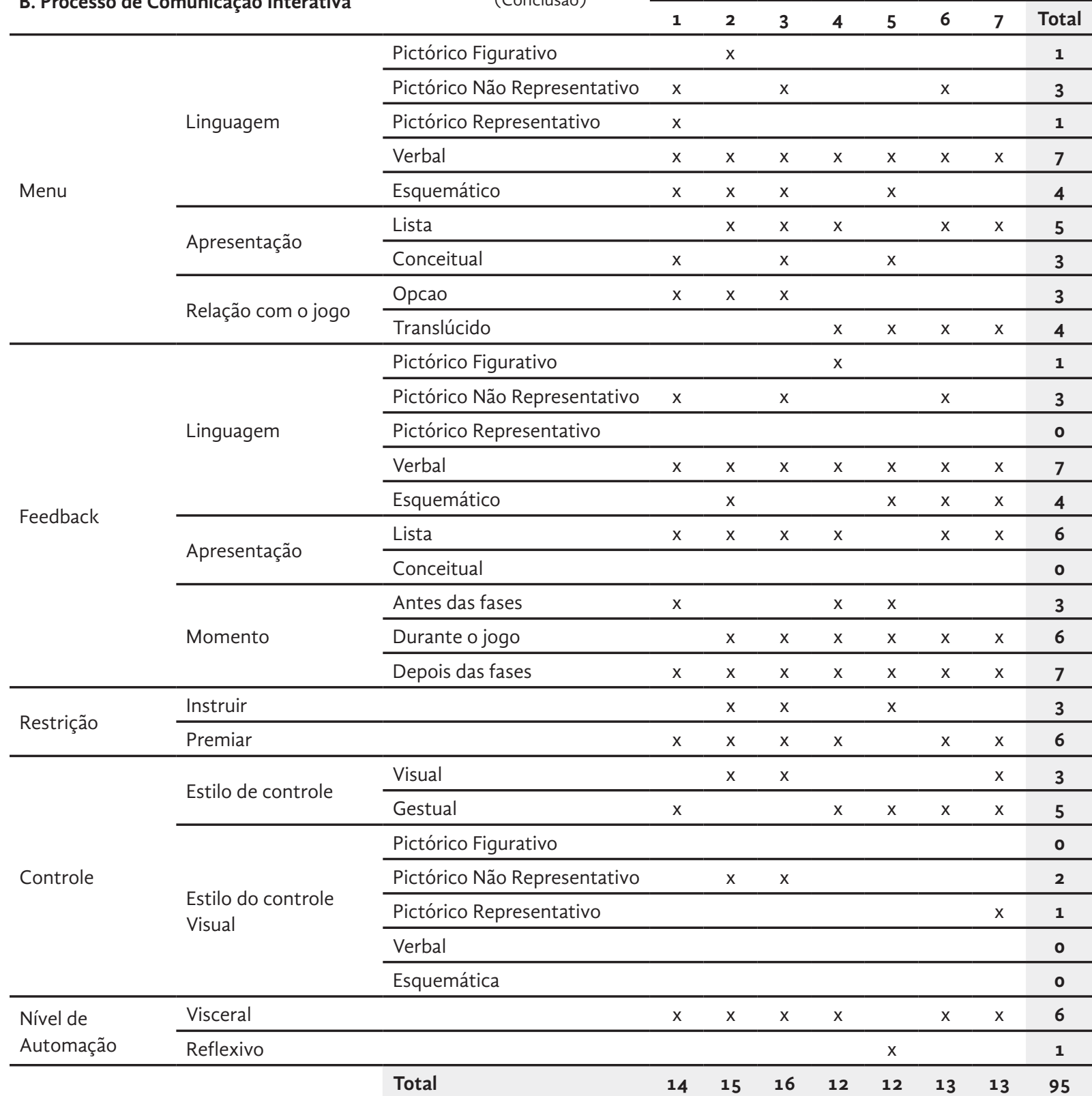

